\title{
Are poor living conditions in childhood and adolescence an important risk factor for arteriosclerotic heart disease?
}

\author{
A. FORSDAHL \\ From the Institute of Community Medicine, University of Tromsø, Norway
}

SUMMARY Norwegian counties show considerable variations in their rates of mortality from arteriosclerotic heart disease. These variations cannot be explained by present-day differences in standard of living. Such differences did exist in the past as was shown by large variations in infant mortality. A significant positive correlation has been found between the county age-adjusted mortality from arteriosclerotic heart disease in people aged between 40 and 69 years and county infant mortality relating to the early years in the same cohorts. The findings suggest that great poverty in childhood and adolescence followed by prosperity, is a risk factor for arteriosclerotic heart disease.

There is no doubt that an overall correlation exists between a low standard of living and total morbidity and mortality. The large mortality reduction in many countries during the past decades has been attributed largely to a concurrent improvement in the 'standard of living', however this should be defined. Similarly, the current large variations in morbidity and mortality between developed and underdeveloped countries probably reflect general differences in living standards.

In Norway, however, there are still considerable variations in mortality among counties which cannot easily be explained by current living conditions*. Admittedly small groups of people lag behind in prosperity, but it still seems justified to claim that people all over Norway today live in circumstances which 50 years ago would have classified them as 'upper middle class'.

The current paper attempts to explain the hypothesis that poverty during adolescence is positively correlated with the risk of dying from arteriosclerotic heart disease. The possibility of such an association has previously been suggested (Forsdahl, 1973; Forsdahl et al., 1974).

The analysis is based on official statistical data. Adjustments have been made for differences in sex and age by means of the direct method of standardisation. The population in Norway at

\footnotetext{
* Registration of mortality by county started in 1871 , comprising all * Registration of mortality by county started in 1871 , comprising al more or less the same until 1969, when two of the counties were combined so that Norway now has 19 counties.
}

1 November 1960, has been used as the standard. The causes of death have been classified in accordance with the 8th revision of the International Classification of Diseases (1967). Associations among rates are expressed as product-moment correlation coefficients ( $r$ ) and as Spearman's rank correlation coefficients $\left(r_{s}\right)$.

\section{Own studies}

The infant mortality, at least in Norway, has long been considered to be a reliable index of the standard of living (Central Bureau of Statistics of Norway, 1961), and it has therefore been used in the current paper. Whereas earlier there were considerable variations in infant mortality among Norwegian counties, these are now negligible (Central Bureau of Statistics of Norway, 1905; $1910 ; 1915 ; 1962 ; 1969)$.

Despite the fact that the previously existing differences in standard of living have generally disappeared, sizeable variations in middle-age mortality can still be found. If county rates for mortality caused by disease (any type) among men aged between 40 and 69 in 1964-67 (Central Bureau of Statistics of Norway, 1974) are compared with the county infant mortality during their childhood and youth operationally defined as 1896-1925, a good correlation is found (Fig. 1), with $\mathrm{rs}_{\mathrm{s}}=+0.93$. In other words, in counties where infant mortality was high, the same generation also had a high mortality in middle age. For 




Fig. 1 Correlation between mortality from diseases (total) 1964-67, in men aged 40 to 69 years (standardised rates/100000 population) and infant mortality rates 1896-1925.

females a similar, but weaker correlation is found $\left(r_{s}=+0 \cdot 75\right)$.

When the different causes of death are examined, arteriosclerotic heart disease shows large intercounty differences (Central Bureau of Statistics of Norway, 1974). It is also quantitatively important, yielding $39 \%$ of deaths in men caused by disease at ages between 60 and 69 and $19 \%$ of deaths in women. If similar comparisons are made a good correlation is found between the mortality from arteriosclerotic heart disease at ages between 40 and 69 and the infant mortality during the early years in the same cohorts. Males are shown in Fig. $2\left(r_{s}=+0.79\right)$, females in Fig. 3 (rs $=+0.61$ ).

County populations in Norway are not large, and mortality varies from year to year because of the small numbers of deaths. In addition to the correlations with mortality during 1964-67 similar correlations were made with data from 1969-72. The results were nearly the same. However, when infant mortality data during 1966-70 were used (Central Bureau of Statistics of Norway, 1962), rather than the infant mortality of the cohorts from which the heart disease deaths are derived, the coefficients became small and nonsignificant (Table 1).

Table 1 also gives Spearman's coefficients for cerebrovascular disease related to infant mortality rates. With the use of the 1896-1925 infant mortality rates the coefficients are large for males, but not for females. Conceivably, this can be taken as an indication of different aetiological patterns in males and females for this disease group.

Recent arteriosclerotic heart disease mortality may be correlated with the entire sequence of

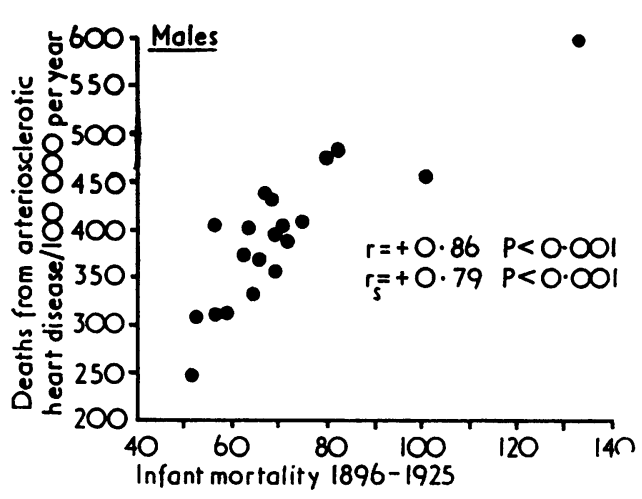

Fig. 2 Correlation between mortality from arteriosclerotic $\vec{\otimes}$ heart disease, 1964-67, in men aged 40 to 69 years ? (standardised rates/100000 population) and infant $\stackrel{\omega}{\longrightarrow}$ mortality rates 1896-1925.

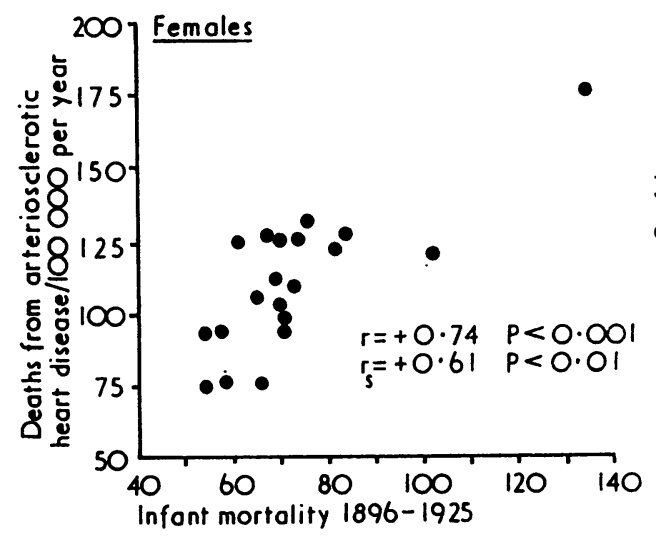

Fig. 3 Correlation between mortality from arteriosclerotic $\stackrel{?}{?}$ heart disease, 1964-67, in women aged 40 to 69 years (standardised rates/100000 population) and infant mortality rates $1896-1925$.

infant mortality rates during the lifetime of the cohorts in question (Table 2). Age is specified in $\frac{7}{0}$ 10-year groups rather than the broad (but ageadjusted) interval of 40 to 69 years in Table 1 . N The county rates are based on small numbers of $N$ deaths, which may explain some of the irregularities in the pattern of coefficients.

In all three age groups for males the infant ${ }^{O}$ mortality during the time that the cohort was $\stackrel{\circ}{\subset}$ aged 0 to 9 years is well correlated to later $\mathbb{Q}$ arteriosclerotic heart disease mortality. The corre- + lation gradually tapers off, and with infant mortality at the time of cohort age of 30 to 39 the coefficients $\frac{\mathrm{D}}{\mathbb{\mathrm { D }}}$ are no longer significant at the $5 \%$ level. For females $\frac{}{8}$ 
there is a suggestion of differences among the three 10-year groups of age at death. Mortality at the age of 60 to 69 years is best correlated with infant mortality.

If the correlation of early infant mortality is examined with other groups of causes of death, varying results are obtained (Table 3 ). The positive coefficients for 'symptoms and ill-defined conditions' are probably due to the cases of sudden death which in Norwegian men have been shown to have the same epidemiological characteristics as deaths from myocardial infarction (Westlund, 1972).

The highly positive correlation in Table 3 for malignant neoplasms was puzzling. Therefore, a special investigation was made of cancer deaths in 1973 and 1974 by means of special, unprinted tables from the Statistical Central Bureau. The results are shown in Table 4.

It appears that the only sizeable correlation is between lung cancer in men and the 1896-1925 infant mortality. No adequate data are available, but it is possible that cigarette smoking by men during the past decades had been more widespread in those counties where the social conditions were previously unfavourable. However, the fragmentary data do not make it likely that present county differences in cigarette smoking are large enough to explain the differences in arteriosclerotic heart disease mortality.

Table 1 Correlation between mortality from selected diseases in men and women at age 40-69 years (standardised rates per 100000 population), and infant mortality rates at different periods. $(1964-67: n=20,1969-72: n=19)$

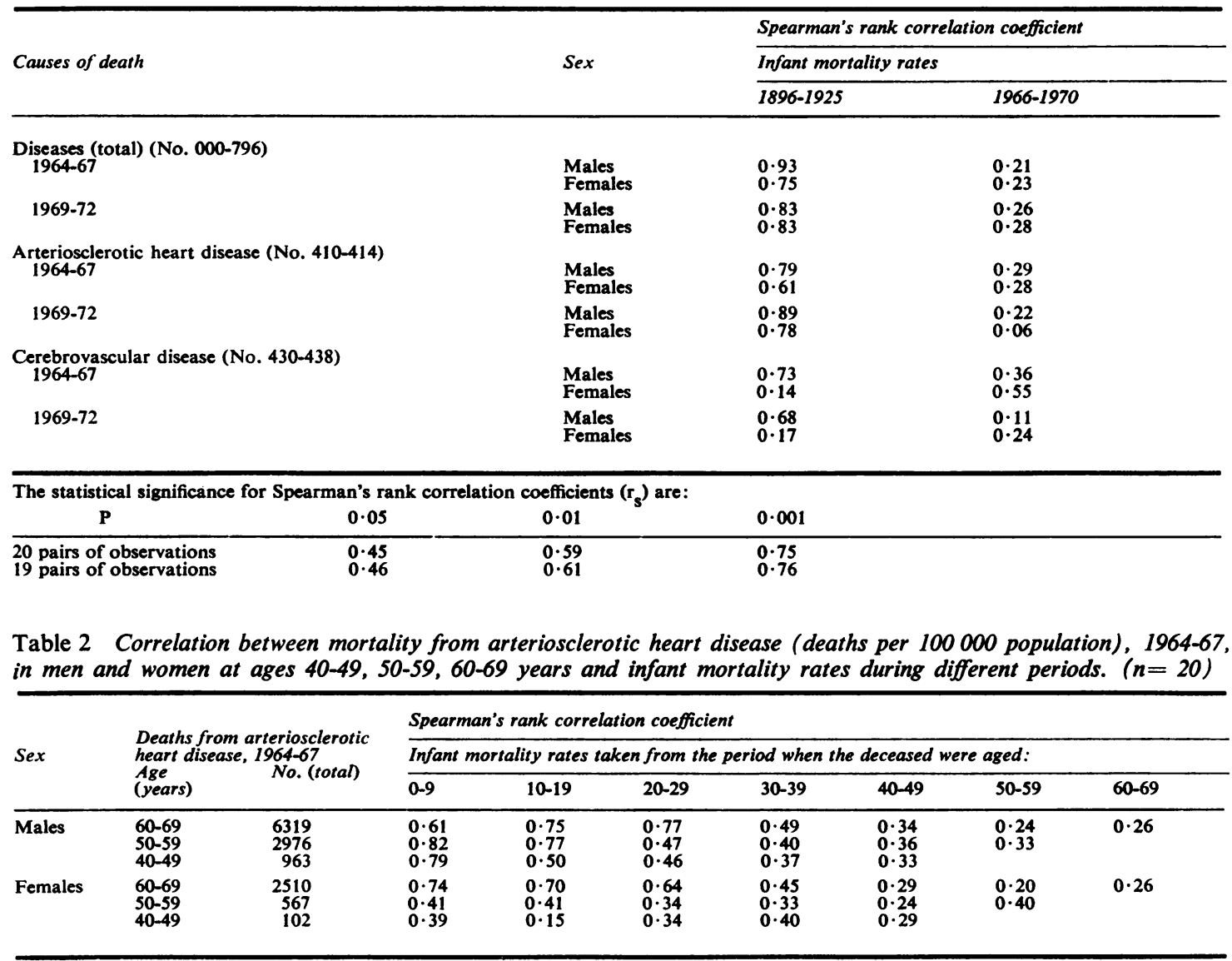

For 20 pairs of observations the statistical significance of the correlation coefficients are:

$$
\begin{array}{ll}
r_{s}=0.45 & P=0.05 \\
r_{s}=0.59 & P=0.01 \\
r_{s}=0.75 & P=0.001
\end{array}
$$


Table 3 Correlation between mortality from selected groups of diseases in men and women at age 40-69 years (standardised rates per 100000 population), and infant mortality rates at different periods. (1964-67: $n=20$, 1969-72: $n=19$ )

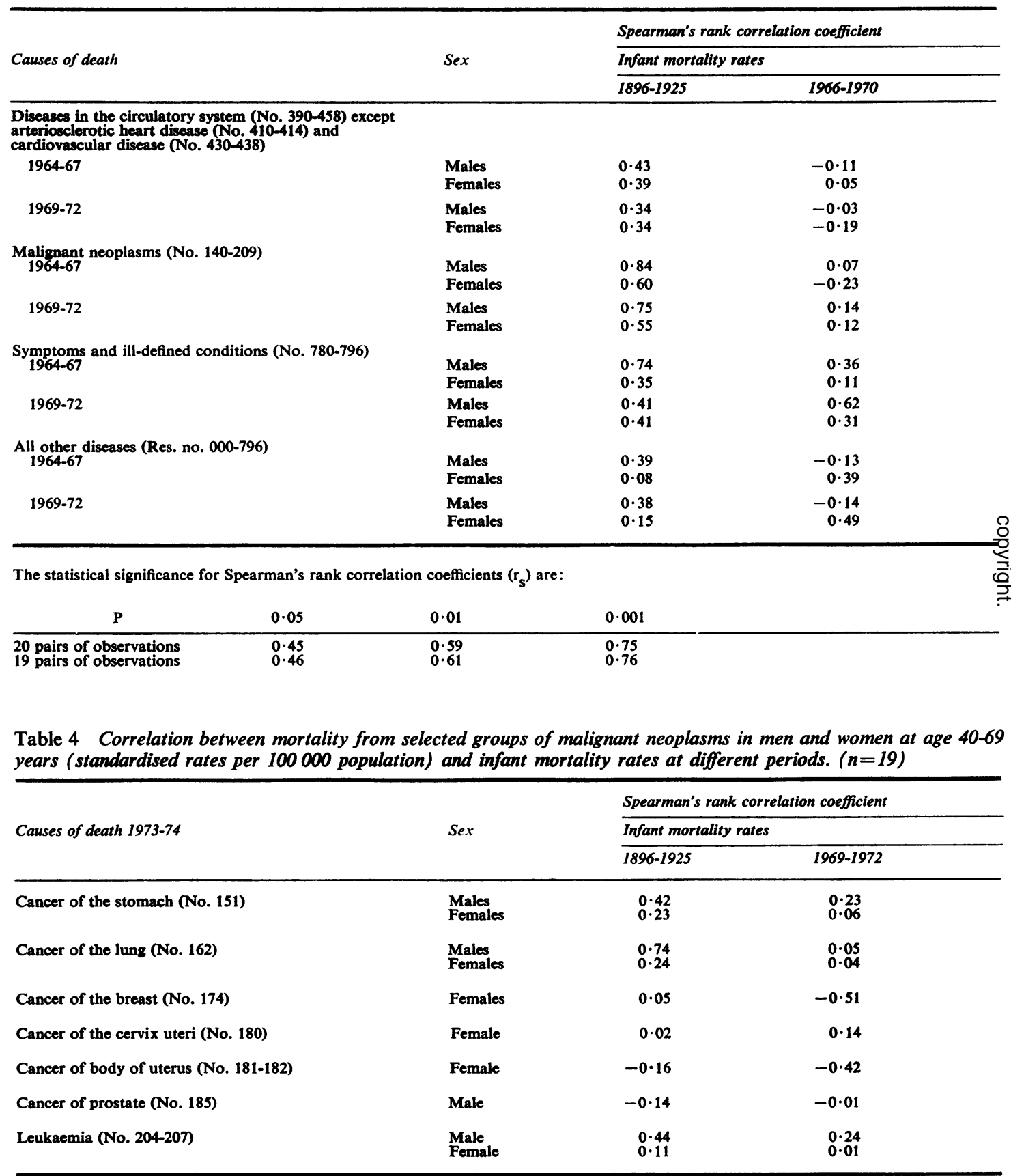

For 19 pairs of observations the statistical significance of the correlation coefficients are:

$$
\begin{array}{ll}
r_{s}=0.46 & P=0.05 \\
r_{s}=0.61 & P=0.01 \\
r_{s}=0.76 & P=0.001
\end{array}
$$


It is also possible that poverty in childhood has resulted in an increased susceptibility to lung cancer.

\section{Discussion}

Some migration has, of course, taken place among the counties. However, as late as 1960 between $80 \%$ and $90 \%$ of the population in most counties were born in the county of residence. Even in Oslo this percentage was well above $50 \%$ (Central Bureau of Statistics of Norway, 1964).

There may be several reasons for the observed association between disease mortality in middle age and the prevailing infant mortality during childhood. Various types of injury to health may add up so as to cause an increased risk of early ageing and death. This is not in contradiction to the Darwinian doctrine of survival of the fittest. Rather, whereas the weaker of the cohort die in infancy, the more fit survive and carry with them a life-long vulnerability because of the poor living conditions in early years.

As mentioned the living standard in Norway has much improved and the county differences have practically been eliminated, as shown by the current infant mortality rates. The relatively large mortality differences in middle age that still exist can therefore hardly be attributed to the living conditions of today. Smoking patterns vary and these may explain some of the differences, but what little information is available on geographical variations in diet does not explain much of the mortality pattern.

It may at first sight seem paradoxical, not that early poverty is associated with later excess mortality, but that arteriosclerotic heart disease should be a major component of this excess. However, the prerequisite is a later exposure to affluence and its consequence in the form of our present way of life. Where this latter condition is not fulfilled-as in the underdeveloped countries-the mortality rates from arteriosclerotic heart disease remain low.

The biological mechanisms that may be involved cannot be identified from the present analysis but it is perhaps possible to speculate. Some form of permanent damage caused by a nutritional deficit may be involved.

Results from previous studies suggest that serum cholesterol may be the intermediate risk factor between an early low standard of living and later arteriosclerotic heart disease (Forsdahl et al., 1974). In other words, our present way of life, with its high fat consumption, tends to increase serum cholesterol more in persons who have grown up in poor families than in those who have not experienced poverty. The hypothetical acquired defect may then be interpreted as a reduced tolerance to fat or specific types of fat.

Another possibility which cannot be completely excluded is that some of the effect of poverty in adolescence is mediated through an increased tendency to smoke cigarettes later in life. Nevertheless whatever the causal relationship may be, the correlation between living conditions in adolescence and later mortality from arteriosclerotic heart disease is so marked that it seems justified to consider a poor standard of living in early years followed by prosperity as a potential risk factor.

Reprints from A. Forsdahl, Institute of Community Medicine, University of Tromsø, N-9010, Åsgård Sykehus, Norway.

\section{References}

Central Bureau of Statistics of Norway (1905). Folkemangdens Bevagelse 1896-1900, IV. Central Bureau of Statistics: Kristiania.

Central Bureau of Statistics of Norway (1910). Folkemangdens Bevagelse 1901-1905, V. Central Bureau of Statistics: Kristiania.

Central Bureau of Statistics of Norway (1915). Folkemangdens Bevagelse 1906-1910, VI. Central Bureau of Statistics: Kristiania.

Central Bureau of Statistics of Norway (1961). Trend of Mortality and Causes of Death in Norway 1856-1955. Central Bureau of Statistics: Oslo.

Central Bureau of Statistics of Norway (1962). Statistical Yearbook 1962. Central Bureau of Statistics: Oslo.

Central Bureau of Statistics of Norway (1964). Population Census 1960, XII, volume VIII. Central Bureau of Statistics: Oslo.

Central Bureau of Statistics of Norway (1969). Mortality Rates in Countries 1964-1967. Central Bureau of Statistics: Oslo.

Central Bureau of Statistics of Norway (1974). Regional Mortality 1969-1972. Central Bureau of Statistics: Oslo.

Forsdahl, A. (1973). Momenter til belysning av den høye dødelighet i Finnmark fylke. Tidsskrift for den Norske Lageforening, 93, 661-667.

Forsdahl, A., Salmi, H., and Forsdahl, F. (1974). Finskættede i Sør-Varanger kommune II. Tidsskrift for den Norske Lageforening, 94, 1565-1572.

Westlund, K. (1972). Myocardial infarction in Oslo 1967-1969. Journal of the Oslo City Hospitals, 22, 77-108.

World Health Organisation (1967). International Classification of Diseases, 8th revision. WHO: Geneva. 